Europe is a rapidly changing world region in all respects, and this has consequences for young people, too. In this opening introductory chapter, the editors outline key distinctive parameters of contemporary modernization in Europe as a whole and indicate the ways in which the following chapters each contribute to a richer appreciation of how modernization is affecting youth transitions.

\title{
Young Europeans in a Changing World
}

\author{
Manuela du Bois-Reymond, Lynne Chisholm
}

The authors in this volume report what it is like to be young in the rapidly changing, enormously diverse world region that is early 21 st-century Europe. The chapters privilege a decidedly sociological analysis of youth as a social and cultural construction and sets of contemporary social and cultural practices characteristic of young people and young adults living in European societies. In doing so, they signal a dual conviction. First, conceptualizing and understanding child and adolescent development also require the more structural perspectives that sociologists bring to macrolevel and microlevel theorizing. Second, the authors in this volume use the terms youth and young people rather than adolescence and adolescents, and they routinely introduce the terms young adulthood and young adults into their analyses. In this way, they underline the importance of research perspectives anchored in the study of the life course as a historically and culturally specific social phenomenon. Furthermore, this phenomenon is firmly situated within the large-scale economic and political change processes currently taking place in Europe and in the global context of Europe as a world region in interaction with other world regions.

As a North American-based series with a largely North American readership, the New Directions series has published content that has naturally centered on North American debates and research findings. This issue

We would like to express our sincere thanks to Lene Arnett Jensen and Reed Larson, who encouraged us to bring this collection to fruition with unswerving enthusiasm and trust in its value. 
presents ideas and information from Europe, with the aim of complementing North American debates and strengthening communication between youth research scholars across the disciplines and across the Atlantic. In the past fifteen years or so, interdisciplinary European youth research has emerged and expanded so that there is both greater permeability between national-linguistic academic discourses and more intercultural, comparative research. Today's European youth research community is lively and dynamic, but it is not well known in North American scholarly circles, with the partial exception of youth (sub)cultural studies or the critical analysis of schooling and social and cultural reproduction. This volume should prompt, then, the professional curiosity of North American specialists in youth studies, particularly those working at the interface of research, policy, and practice.

\section{Language, Culture, and Research Discourse}

English has become the global scientific lingua franca. This has set the direction for Europe, where English increasingly dominates scientific discourse. This means that linguistic flexibility has effectively become a core professional competence for European youth research specialists who work interculturally and comparatively. At the least, they must be able to read the research literature in two and preferably three languages. This is simply not the case for most North American scholars, whatever their discipline, and they are much less likely to be aware of important and interesting ideas and information coming from Europe. These ideas could stimulate and enrich North American discourse, just as the Europeans' facility with English self-evidently contribute to European discourse through the combined Anglo-American literature.

However, language is by no means simply a technical communication tool: it carries and expresses cultural meanings to which multiple language skills by definition open access, at least in principle. Grasping and working with cultural meanings are definitive features of the construction of knowledge in the humanities and social sciences (and, many would now argue, in the natural and applied sciences). Cultural and linguistic diversity is Europe's hallmark; in many ways, this defines Europeans' understandings of the world region in which they live.

From within their own locations and in communication with each other, Europeans hence approach the "youth question" in distinctive ways among themselves and in comparison with North Americans. This does not mean that European and North American societies and discourses share little; quite the reverse. At the same time, their respective contexts and priority issues diverge, possibly along some key dimensions, although this is a question better addressed through greater future cooperation and discussion between the two regions' youth research scholars. For the moment, we 
might simply conclude that the complexity of European patterns of culture as expressed through multiple European youth research literatures is a less accessible source of knowledge for most North American specialists.

\section{Change and Diversity in Europe}

Since the 1980s, a significant rise has occurred in Europe in both the empirical range of diversity and the cultural perception of diversity within its expanding economic and political borders. The demise of the Soviet bloc and the democratic transformation of central and eastern Europe from 1989 gave, step by step, Europe back to itself. "Western" and "eastern" European societies came to recognize each other once more, beyond the schematic stereotypes of the cold war era and the memories of Europeans old enough to remember the early decades of 20th-century Europe. This alone has had a remarkable effect, not least for young people in Europe, for whom a whole new world opened up virtually overnight—and this goes in both directions, it should be underlined.

Not only European integration processes (formally represented by European Union Treaties and EU enlargements) but also the consequences of economic and cultural globalization (expressed in changing patterns of migration into Europe and through information technology, media, and commerce) have equally contributed to changing the face and the meanings of diversity. Concerns about the real or imagined prospect of cultural and political "standardization" tend to prevail in political and public debate, particularly among (older) adult citizens and commentators. However, on the whole, young people are more inclined to enjoy the variety that is available, although they typically prefer to remain on their home ground while doing so-with the exception of holidays abroad, which most wish for and many take. In effect, we begin to detect here life-phase-related (and possibly ultimately intergenerational) differences in the ways in which Europeans manage the tensions and ambiguities between national-cultural specificities and transnational commonalities.

All the points addressed so far are relevant for the modernization of youth transitions in Europe. The contributions to this collection present a set of pictures of youth in today's Europe, and each sets its picture into a common frame: (a) the diversity of national cultures and (b) traditions interacting with common problems such as new multiculturalisms as a consequence of European integration and globalization.

\section{Three Key Dimensions of Change}

In this collection, describing and analyzing the modernization of youth transitions in Europe take their cue from three key dimensions of change in young people's lives: 
1. Changing relations between education, training, and the labor market: what does this mean for young people's learning and working trajectories?

2. Changing relations between the generations: what does this mean for patterns of dependence and autonomy between parents and children?

3. Changing time and space relations: what does this mean for young people's perceptions of their future lives in a world in which real-time virtual communication reaches across physical space and proximate locations can be ever-more readily exchanged for distant, unfamiliar, and yet real-life study, work, and travel experiences?

The initial driving force for the application of contemporary modernization theory in youth studies was the emergence of high youth unemployment rates after the mid-1970s, followed by structural change in the youth labor market toward a greater likelihood of vulnerable employment (part-time and temporary work, underemployment and multiple jobs, public-subsidy programs). Over time, youth transitions between schooling and employment became increasingly protracted and fragmented for higher proportions of youth cohorts. Formal education and training qualifications, hence, came to play an ever-stronger role in prefiguring life chances and risks. Gradually, higher participation rates in education and training served to postpone the labor market-entry problem, to set credential inflation into motion, and to intensify polarization processes in general. By the 1990s, it had become abundantly clear that school-to-work transitions are one element of broader modernization patterns relating to youth within the life course as a whole. This was the starting point for the kind of research reported in this volume.

Youth unemployment is a recognized problem in North America, but explicit links with the sociological analysis of contemporary modernization have not taken a prominent role in the literature; Côté (2000) and Arnett (2004) are notable recent exceptions. In Europe, on the other hand, youth researchers have developed the concept of a new youth biography. This term refers to the consequences of the deconstruction of standard biographies, which were based on a three-phase social life course: socially differentiated education and training; gender-differentiated work lives, founded in full and continuous employment for men and mainly family responsibilities for women; and age-defined retirement for men and continued family responsibilities for women.

Today's emerging "choice biographies" imply that whereas social origin and gender are still relevant in a range of ways, they no longer exercise the same kind of aggregate prestructuring of education, training, and employment trajectories as they used to do. Biographical individualization, which has both objective and subjective dimensions, means that social factors (class, gender, ethnic origin) impact youth in subtler and more differentiated ways. Social factors equally bring greater risks and contingencies for each and every person as an individual subject. Risk and choice are bound together through life. 
It is important to add that these ideas, together with the initial research that accompanied their development, originated during the 1980s in more affluent continental western Europe and the Nordic countries. They spread during the 1990s to the British Isles and Ireland (where more purely neo-Marxist approaches had held greater influence) and then to southern, central, and eastern Europe. This might well be regarded as an example of the development of discursive hegemony in European intellectual life and, furthermore, one that did not derive from the Englishlanguage theoretical literature in the first instance; rather, it derives from German-language discourse and its influence in Dutch and Nordic scientific communities.

The dynamics of European transformation and integration routinely produce tension around the dialectic of continuity and discontinuity: European polities are caught up in the turmoil; their young people experience it first hand and try to negotiate pathways through a world that those born only two or three decades earlier would have found hard to imagine in their own youth. European youth researchers, for their part, have had to work out new theoretical, methodological, and empirical approaches to deal with the panoply of old and new diversities. This is the practical context in which intercultural and comparative youth research in Europe has developed.

\section{The YOYO and FATE Projects}

The contributors to this volume all belong to this young community of European youth research. In the past decade, they have worked together in many ways, not least in a series of projects that have covered ten countries from all parts of Europe: Ireland, the United Kingdom, Denmark, the Netherlands, Germany, Bulgaria, Romania, Italy, Spain, and Portugal. As projects funded by the European Commission's Research Framework Programs, they must deliver policy-relevant findings and are intended to contribute to building a European-wide research area.

This collection draws in particular on the YOYO and FATE projects, which are both acronyms and metaphors at the same time. ${ }^{1}$ The acronym YOYO stands for the project title Youth Policy and Participation: Potentials of Participation and Informal Learning for Young People's Transitions to the Labor Market. The acronym also connotes the child's yo-yo, which represents young people's lives swinging up and down and back and forth time and again in changing curves and rhythms through to adult life and hence no longer conforming to the standard biographical patterns described earlier. Young people's fates in transition, on the other hand, are bound up with those of their families, whose capacities to support their children during this critical period of development and change in their lives are highly diverse and subject to influences often beyond their direct control; hence, the FATE project's title: Families and Transitions in Europe. 
The notion of transition delineates the common conceptual anchor for these projects' research-based efforts to understand how young people in Europe approach, shape, and realize their life plans. The YOYO project researchers focused on documenting destandardized school-to-work transitions and the effects these have on youths' access to citizenship and on their motivation to continue participating in education and training in the future. The researchers surveyed how youth, education, and labor market policies succeed and fail to motivate young people for active engagement in shaping their own transitions. The results show that policy measures can enhance motivation where they explicitly foresee opportunities for individual choices and spaces for experimentation and where they include nonformal educational elements.

The FATE project investigators examined the role of family support in young people's transitions to economic, household, and personal autonomy. They placed their research in the context of reduced public benefits and subsidies for young people in most European countries together with persistently high rates of youth and adult unemployment in many countries and regions. The situation of young people in eastern versus western Europe was a priority focus in the FATE project: the transition to market economies brought momentous changes for the social organization of school-to-work transitions and family support measures in the former socialist state countries.

\section{Contributions to This Volume}

In the first contribution to this collection (Chapter 2), Lynne Chisholm sets the framework within which European youth research has developed, with reference to the European policy environment. She notes the key thematic dimensions of research agendas, offers an account of how theory and research have developed and matured since the 1990s, and draws attention to the specific methodological and professional challenges of doing European youth research. The author concludes with some reflections on how interdisciplinary youth research might respond cogently to the issues and problems of these turbulent times.

We noted earlier that extended participation in initial education and training has acted as a key intermediating factor in the modernization of youth transitions in Europe. This obviously speaks to the first key dimension of change noted earlier. Translated into active, subject-related terms, this means that learning is currently at the top of educational and political agendas across Europe and at all levels. But how should learning be conceptualized in today's fast-moving world, and what are the most promising ways to develop young people's learning potential? Sven Mørch and Manuela du BoisReymond in Chapter 3 argue that established ways of organizing schooling and learning are no longer appropriate or effective for emerging knowledgebased societies. Learners are reclaiming their integrity, and young people readily list their dissatisfaction with existing forms of institutional, curricular, and 
pedagogic provision. What kinds of new learning concepts and practices are available? The authors discuss the relationship between formal, nonformal, and informal learning and pay attention to the innovative potential of "trendsetter learners" who carve out their own learning trajectories.

Today's young people experience an extended youth characterized by risks and contingencies, quasi-autonomies, and gendered tensions and ambiguities. Individualized biographies and the embryonic emergence of a new social life phase, termed young adulthood, place into question whole sets of conventional expectations about what life is likely to bring about-in both the short term and the long term. Should we not suspect that their ideas about young people's futures diverge from those of people several decades older than themselves? Might we be the witnesses of a sea of change in the cultural understanding of time or of lifetimes? Carmen Leccardi (in Chapter 4) explores the concept of time and future lifetime for young adults, showing how they are inclined not to plan what is no longer susceptible to planning. In other words, she demonstrates how young people apply an immanent, ephemeral rationality to the notion of the future and its "(un)controllability." Leccardi's contribution thus focuses on the third key dimension of change: changing time and space relations.

Young Europeans in the future may experience different kinds of learning environments and processes, but it is unlikely that they will experience shorter periods of initial education and training than they do today. One of the consequences is already and will certainly continue to be that young people's economic dependence on their families and households of origin will last longer than was typically the case in the second half of 20th-century Europe. Earlier, parental households in the mass of the working population favored young single people's continuing coresidence because this brought extra income once they had moved into the labor market. Now, most young people of all social backgrounds remain at least partly financially dependent on their parents for longer periods-sometimes for much longer and well into young adulthood. This places a new burden not only on parents (and sometimes siblings and grandparents) but also on the young people themselves, who experience fragmented and partial forms of autonomy. Here we refer in particular to the second key dimension of change: that is, changing relations between the generations. Hence, Andy Biggart and Siyka Kovacheva (Chapter 5) analyze the nature and scope of the demands on and the deployment of family resources in relation to young people's needs and wishes. In doing so, they set their findings in the framework of social capital theory.

Barbara Stauber's contribution in Chapter 6 combines two key ideas that inform contemporary youth research in Europe. First, she posits that being a girl or a boy and then becoming a woman or a man have lost their traditional significance in the sense that they are no longer selfevident, unquestioned identities, roles, and practices. This is another way of approaching our third key dimension of change: changing spatial relations can also refer to the repositioning of gender relations in terms of the 
drift away from binary toward overlapping and contingent concepts and practices. The very term gender connotes the problematic quality of femininity and masculinity in today's world. In other words, these concepts have accreted multiple potential meanings and consequences for personal and social action. They have to be continually negotiated within continually changing contexts of identity and practice. Second, Stauber reminds us that the capacity and competence for negotiating identities and behaviors have to be learned. This addresses our second key dimension: changing relations between the generations from the standpoint of shifting balances between primary and secondary sources of gender socialization. Today, negotiating processes are more flexible, involve a wider range of actors, and take place through action itself, through "doing gender," and above all, in informal learning settings, both among peers and at the workplace.

Chapter 7 takes us back to the starting point of youth researchers' priority concerns -in other words, back to changing relations among education, training, and the labor market, our first key dimension of change. Using the results of the YOYO project, Andreas Walther and Wim Plug analyze the features and implications of destandardization and individualization against the background of structural change in youth labor markets.

\section{Conclusion}

Fifty years from now, it might be instructively entertaining to look back to a time when so many longstanding values and assumptions about lifecourse transitions between youth and adulthood underwent so much change. We predict that the sequential relations among education, training, and employment will have been transformed into more fluid and open patterns that bear no necessary correspondence with life phase. We think it likely that adulthood, as an amorphous and no longer clearly defined concept and practice, will be well on the road toward deconstruction and reconstruction in novel ways yet to be described and understood. In turn, this will certainly reflect back on the social construction of youth, and this is the point at which to bring our reflections to a close: we have, as yet, no evidence, and our theories cannot predict the future. We hope, however, that this modest contribution will foster greater cooperation between European and North American youth researchers. What would we most like our readers to carry forward with them after having made their way through this collection? There are two central ideas that we wanted this collection to convey. First, studying social and cultural diversity-here represented by contemporary Europe-is a rich source of theoretical inspiration. Second, youth as a life phase is neither an immovable feast nor an inevitable plague. It is a social and cultural construction within a historically specific phenomenon: sociologically speaking, it is time to bring youth back into the life course. 


\section{Note}

1. Both projects were carried out between 2001 and 2004. For the YOYO project, Walther, du Bois-Reymond, and Biggart (2006) conducted an analysis of youth work and vocational integration policy measures in combination with interviews with young people, project personnel, and other social stakeholders. For the FATE project, Biggart (2005) conducted a questionnaire survey and qualitative interviews with young people and their parents.

\section{References}

Arnett, J. J. (2004). Emerging adulthood: The winding road from the late teens through the twenties. New York: Oxford University Press.

Biggart, A. (2005). Families and transitions in Europe: Final scientific report. Coleraine, Ireland: University of Ulster.

Côté, J. E. (2000). Arrested adulthood: The changing nature of maturity and identity. New York: New York University Press.

Walther, A., du Bois-Reymond, M., \& Biggart, A. (2006). Participation in transition: Motivation of young people for learning and work. Frankfurt/Berlin/Bern: Lang.

MANUELA DU BOIS-REYMOND is professor emeritus of education and youth studies at the University of Leiden in the Netherlands. Her fields of interest concern intercultural youth and childhood studies in the fields of intergenerational relationships, youth transitions, and new forms of learning.

LYNNE CHISHOLM holds the chair for education and generation at the University of Innsbruck's Institute of Educational Sciences, Innsbruck, Austria, and is director of the institute. She specializes in the comparative and intercultural study of education, training, and youth, including the intersections between research, policy, and practice in these fields. 